\title{
Beobachtungen der Planeten (144) Vibilia und (145) Adeona.
}

Am 3. d. M. fand ich, wie durch den Telegraphen an die europäischen Astronomen mitgetheilt worden ist, zwei neue Planetoiden, denen ich auch sogleich, unter der Voraussetzung, dass keiner davon mit den verlorenen Dike und Camilla identisch sei, Bezeichnung und Namen beigelegt habe. Die folgenden Beobachtungen sind mir bis dabin gelungen.

(144) Vibilia; Grösse 10.2.

${ }_{\mathrm{Jani}}^{\mathbf{1 8 7 5}}$ H. C.m. Zt.

$\mathrm{Vgl} . \log \left(\mathrm{p}^{\prime \prime} \triangle\right)$

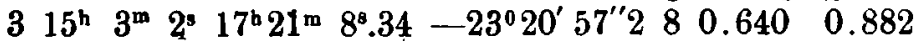

$\begin{array}{llllllll}411 & 1758 & 20 & 18.75 & 21 & 37.3100 .330 n & 0.906\end{array}$

$\begin{array}{llllllllll}911 & 1154 & 15 & 15.64 & 25 & 16.210 & 0.196 n & 0.909\end{array}$

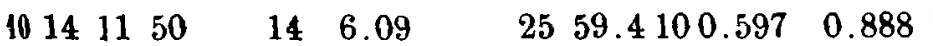

$\begin{array}{llllllllllll}13 & 11 & 38 & 3 & 17 & 11 & 7.30 & -23 & 27 & 40.4 & 109.171 n & 0.912\end{array}$

(145) Adeona; Grösse 11.5.

$\begin{array}{llllllllllllll}3 & 14 & 41 & 7 & 17 & 16 & 6.85 & -23 & 4 & 18.9 & 3 & 0.594 & 0.888\end{array}$

$\begin{array}{llllll}4 & 11 & 44 & 7 & 15 & 14.10\end{array}$

$641.0100 .073 n 0.909$

$\begin{array}{llllll}9 & 11 & 40 & 56 & 10 & 9.13\end{array}$

$\begin{array}{llllll}19 & 33.6 & 6 & 9.714 n & 0.912\end{array}$
${ }_{J u a t}^{1875}$ H.C. m.Zt.

$\begin{array}{lllll}.58 & -23022^{\prime} 10^{\prime \prime} 78 & 0.113 & 0.910\end{array}$

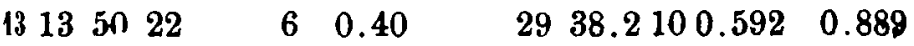

Hierbei sind Werthe für die Positionen der Vergleichsterne zu Grunde gelegt, so gut ich sie jetzt auswählen konnte. Brauchbare Vergleichsterne finden sich in dieser Gegend des Hinımels nur noch äusserst dürftig, und dic benutzten habe ich vorläufig an ein paar Sterne aus Argelander's südlichen und den nicht sehr verlässlichen Washingtoner Zonen angeschlossen.

Die Beobachtungen der ersten Nacht, besonders von der Adeona, sind nicht sehr gut, theils wegen der Schwäche der Planeten nahe vor Tagesanbruch, theils weil, eben erst von der Reise nach Neu-Seeland zurückgekehrt, Beobachter sowohl wie Instrument noch nicht ganz wieder in gut arbeitsfähigem Zustand sich befanden.

Litchfield Obs. of Hamilton College,

Clinton, N.-Y., 1875, Juni 14. C. מ. F. Peters.

Comparison of Elements of $\tau$ Ophiuchi with Pulkowa Observations.

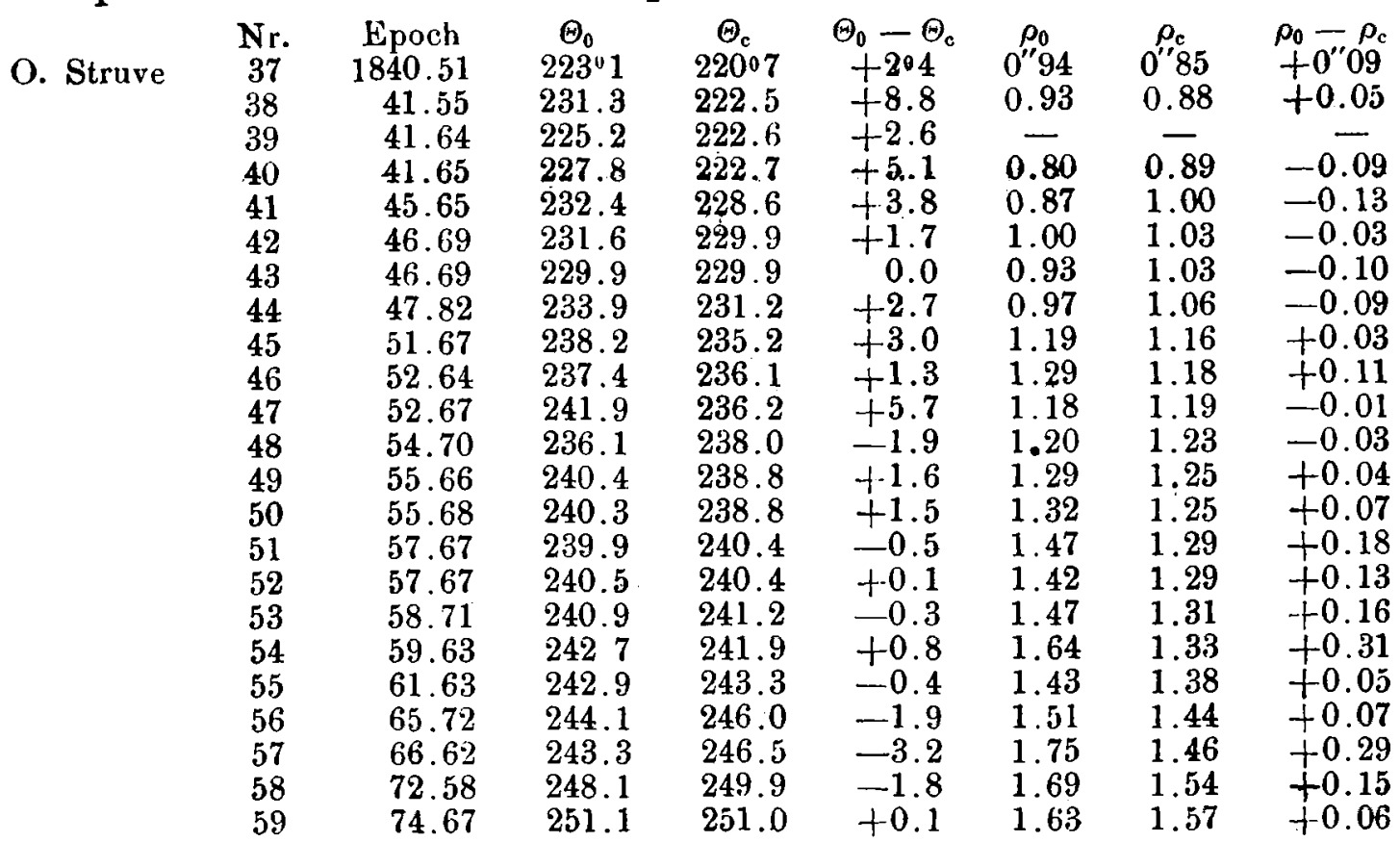

I am indebted to Mr. Dubjago for sending me these measures. The systematical corrections have been applied after: Bulletin de l'acad. des sciences de St. Petersbonrg, t. XII (1866).

Markree-Observatory, 1875, June 16.

W. Doberck.

Ein junger Mann, phil. nat. cand., der in Holland Facultas docendi besitzt für Mathematik in allen Klassen einer Realschule I. Ordnung, sucht eine Stelle als Junior-Assistent an einer Sternwarte. Offerten unter H. 02485 befördert die Annoncen-Expedition von Haasenstein \& Vogler in Hamburg. 